\title{
Implementing New RAM Initiatives In Army Test And Evaluation
}

\author{
Ken Dalton, U.S. Army Evaluation Center \\ J. Brian Hall, Ph.D., U.S. Army Evaluation Center
}

Key Words: design for reliability, reliability growth, reliability program scorecard, contract language

\section{SUMMARY}

This paper describes the processes for implementing new Department of the Army (DA) reliability policy directives [1] issued by the Assistant Secretary of the Army for Acquisition, Logistics, and Technology, or ASA(ALT). It highlights key points of the implementation guide [2] prepared by the U.S. Army Evaluation Center (AEC) and the U.S. Army Test and Evaluation Command (ATEC). The implementation plan herein utilizes GEIA-STD-0009 [3] for developing contract language promoting reliability best practices. The Army Materiel Systems Analysis Activity's (AMSAA's) new Reliability Program Scorecard [4] is used for performing early-on engineering evaluations of contractor reliability engineering activities. Note that both of these tools are outcomes of the Department of Defense (DoD) Reliability Improvement Working Group (RIWG) [5]. The implementation plan also addresses the Defense Science Board (DSB) recommendation [6] and the new DoD acquisition regulations [7] to establish Reliability Growth (RG) programs for developmental systems. Growth programs and associated planning curves are constructed via AMSAA's Planning Model based on Projection Methodology, hereafter referred to as PM2 [8, 9]. Finally, AMSAA's COnsumption, HOlding, Repair and Transportation (COHORT) cost model $[10,11]$ is utilized to identify life cycle cost impacts for systems that breach their established reliability thresholds.

\section{INTRODUCTION.}

\subsection{Background.}

There is a wealth of anecdotal and empirical evidence showing that a significant number of U.S. Army systems over the last decade have failed to demonstrate their established reliability requirements during operational testing. In light of the DSB report [6], and the DoD RIWG report [5], this problem is not unique to the Army, but is a phenomenon that has occurred throughout the DoD. In order to address this problem for Army systems, the ASA(ALT) established a reliability policy [1] to serve as a mechanism by which challenged programs may be identified early in the test and evaluation process (i.e., early in the Engineering Manufacturing and Development (EMD) phase of the Defense Acquisition Management Framework). Additionally the DoD has issued policy guidance directing all programs to have viable RG strategy as an integral part of design and development [12]. Figure 1 shows the applicable DoD and DA directives and guidelines that have been issued since December 2007 that are aimed at improving how DoD address reliability during design and development. It should be noted the Weapon Systems Acquisition Reform Act (WSARA) of 2009 [13] has placed increased emphasis on product reliability throughout the development process. Section 454 of the WSARA assigns specific responsibilities to Office of the Secretary of Defense (OSD) Director for Systems Engineering (DSE) and the Director for Development Test and Evaluation (DDTE) to evaluate Service Acquisition Executive (SAE) plans for ensuring the development of robust RAM implementation programs and requires OSD to report to Congress on the progress being made in the implementation of RAM improvements.

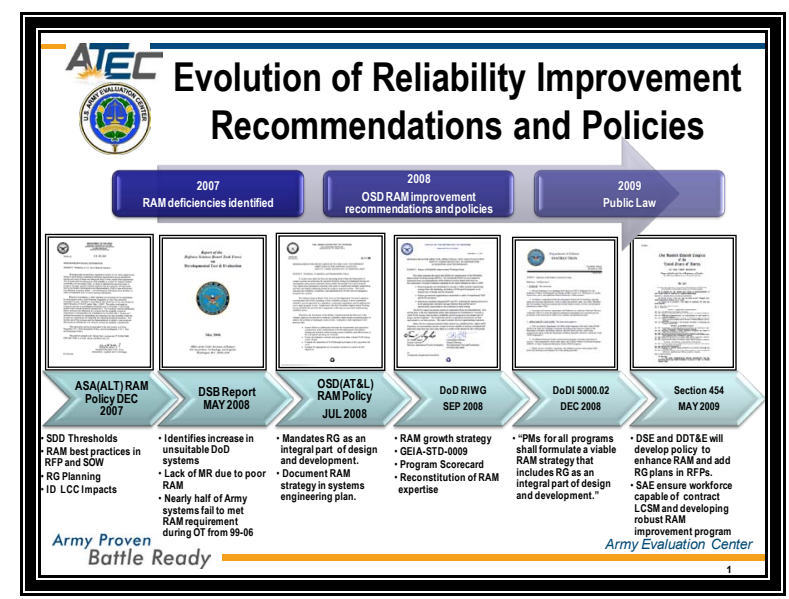

Figure 1. Evolution of RAM Policies.

\subsection{Applicability.}

The central theme throughout the new DoD and DA reliability initiatives is the need for development programs to have viable Reliability Program Plans (RPPs). Experience has shown time and again that development programs without viable RPPs will, more than likely, fail to meet reliability requirements. Failure to meet reliability goals requires additional time and resources to correct reliability deficiencies. A critical aspect of a reliability program is the establishment of periodic goals, or thresholds, that management can use to track the progress of a development effort and, if necessary, make periodic program adjustments, thereby avoiding lengthy and costly program delays. This paper goes over specific steps that have been identified as being critical pieces of a RPP. Section 2 discusses the procedures that have been developed for implementing the ASA(ALT) policy directives. Section 3 provides details on 
Design for Reliability (DFR) principles, RG management and methodology, contract language promoting reliability best practices, and methodology for assessing contractor reliability engineering processes.

\subsection{POLICY IMPLEMENTATION STEPS}

\subsection{Implementing Policy during Design and Development.}

Figure 2 illustrates the five step implementation plan of the ASA(ALT) reliability policy [1]. The five steps include: (1) establishing the test threshold for the system; (2) documenting the threshold value; (3) developing the necessary reliability growth plans; (4) performing the threshold assessment and; (5) reporting the results. Each of the activities displayed on this chart have footnotes to identify the various Army organizations involved, i.e., responsible stakeholders. These organizations include: (1) the materiel developer or PMO/PM; (2) the Army's independent RAM Evaluator, AEC-RAM; (3) the Army's independent Integrated Logistics Support (ILS) Evaluator, AEC-ILS; (4) the AMSAA Reliability Branch; (5) the AMSAA Resource Studies Branch and; (6) the Training and Doctrine Command (TRADOC), the Army's combat developer.

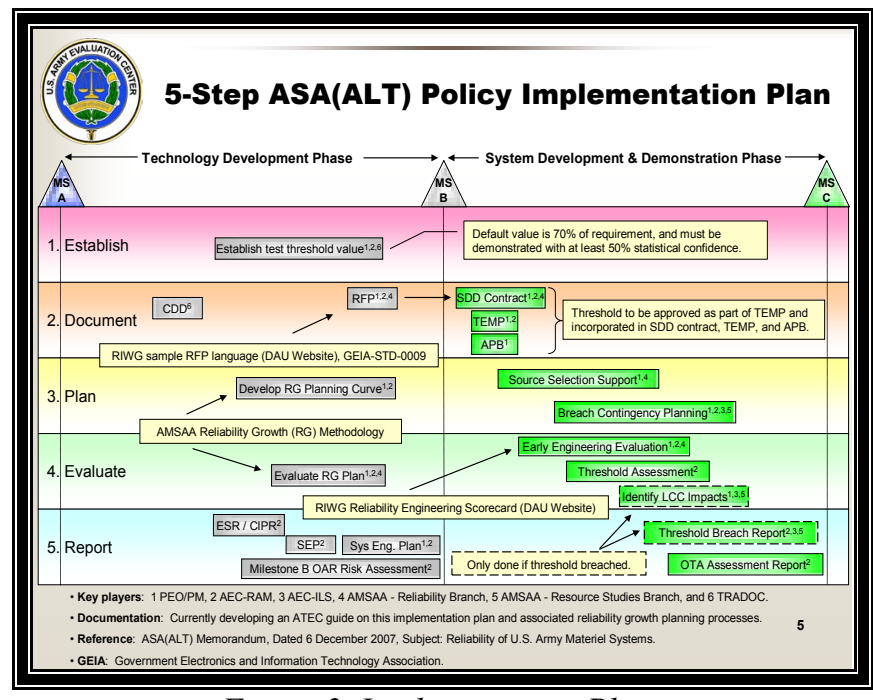

Figure 2. Implementation Plan.

The core elements of the five step process involve establishing the reliability test threshold value, creating the plan to achieve the reliability threshold, and evaluating the progress being made at achieving interim and final reliability goals. Sections 2.2 through 2.5 discuss the processes involved in each of the aforementioned steps.

\subsection{Development of Reliability Test Threshold.}

The intention of the reliability test threshold is to serve as an early warning mechanism to identify when programs are off track relative to reliability achievement. The RAM Subgroup of the Test and Evaluation (T\&E) Working Integrated Product Team (T\&E WIPT) is responsible for establishing the test threshold prior to the Milestone B decision point. The default value of the threshold is 70 percent of the Mean Time Between Failure (MTBF) requirement specified in the program's requirements document. The threshold value must be demonstrated with at least 50 percent statistical confidence by the end of the first full-up, system-level Development Test (DT) event in the EMD phase. The RAM Subgroup of the T\&E WIPT must define the scheduled test phase that constitutes this DT event. Finally, the policy requires that the threshold value be approved as part of the Test and Evaluation Master Plan (TEMP), and recorded in the EMD contract, as well as the Acquisition Program Baseline (APB) at Milestone B.

\subsection{Reliability Growth Planning.}

Developing a detailed RG program for developmental items and associated RG planning curves are key elements of many development programs for complex systems. To do this, the RAM Subgroup typically conducts one or more working-level meetings to solidify the T\&E resources needed to ensure that the test program has a reasonable chance of success in maturing the reliability of the system. The first aspect of RG planning includes identifying:

- The number of planned test phases throughout the entire test program;

- The number of scheduled Corrective Action Periods (CAPs), and their planned duration in terms of calendar time;

- The number of prototypes that will be placed under test in each phase;

- The number of test hours per prototype per test phase;

- The initial, interim, and final reliability goals to be achieved.

The RAM Subgroup will must work with the contractor to determine if assumed levels of average fix effectiveness and Management Strategy (MS) for growth planning are reasonable in the view of each of the vendors competing against the acquisition. Once these $T \& E$ details are established, they may be used to develop a RG planning curve. The value of RG planning curves is threefold:

- They portray the planned reliability achievement of an item as a function of test time, calendar time, and other program resources;

- They serve as a baseline against which demonstrated reliability values may be compared;

- They quantify the feasibility in the test program in achieving its interim and final reliability goals.

Figure 3 below shows an example of a PM2 [8,9] reliability growth planning curve for a current Army system.

Construction and evaluation of proposed RG plans are facilitated by a wealth of RG planning methodology developed by AMSAA. An overview of RG, a discussion of the relevant literature available for RG planning, as well as a detailed RG planning example for a current Major Defense Acquisition Program (MDAP) is given in the ATEC implementation guide [2].

\subsection{Threshold Assessment and Breach Process.}

Figure 4 illustrates the sequence of actions that will take place following the threshold assessment. Note that the policy [1] 


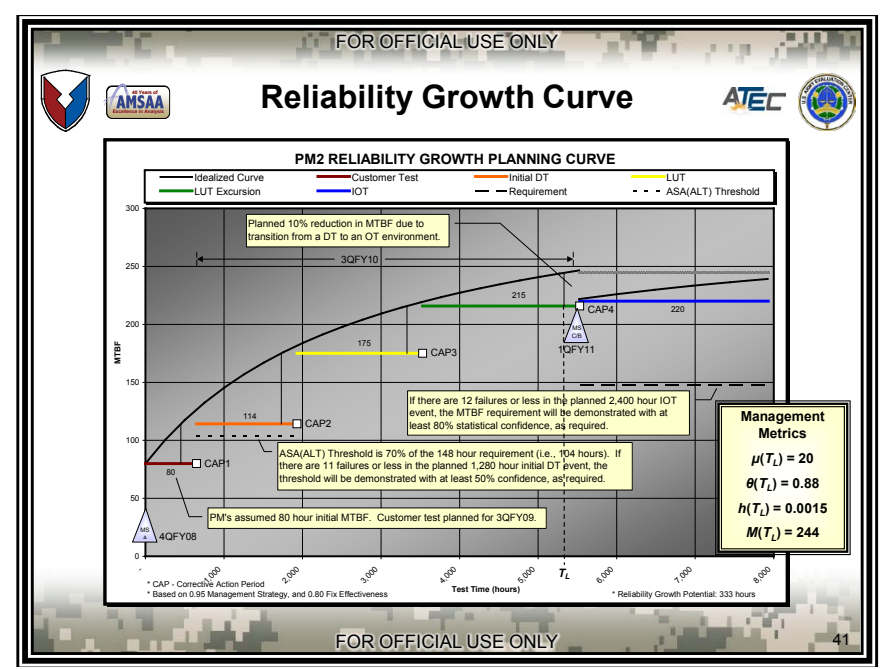

Figure 3. PM2 Reliability Growth Curve.

identifies various agencies to take specific actionsin the event of a threshold breach, and that this process only applies to preMilestone B programs that are JROC Interest. If the system successfully demonstrates the threshold value with at least 50 percent statistical confidence, the assessment results will be documented in an appropriate ATEC product, and reported to the relevant stakeholders, e.g., Program Management Office (PMO), ASA(ALT), AMSAA, Test and Evaluation Organization (TEO), TRADOC etc.

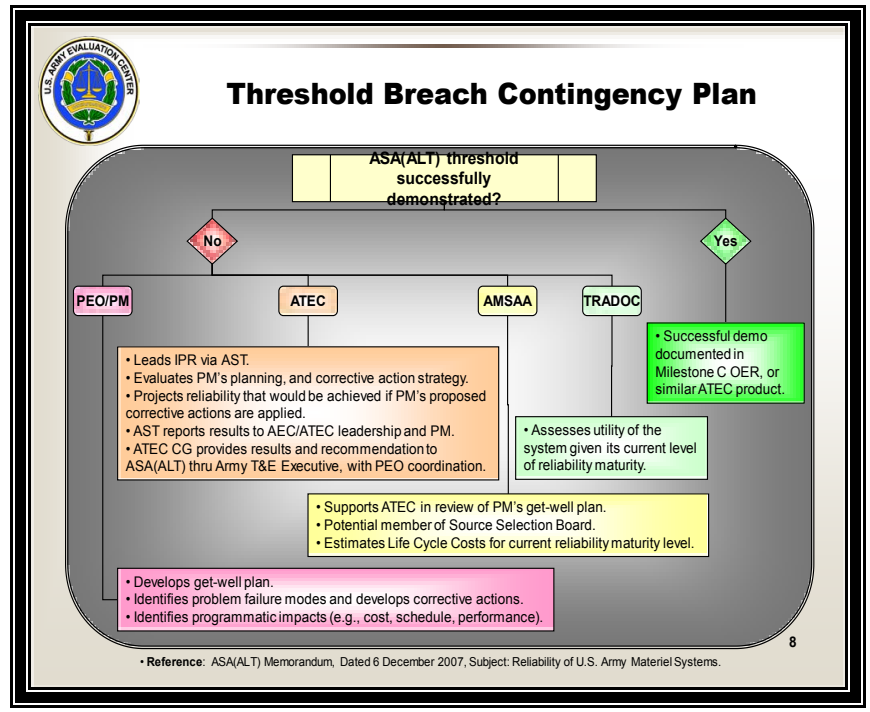

Figure 4. Threshold Breach Process.

If the system fails to demonstrate the test threshold, the following organizations will take specific actions:

- PMO. The PMO is responsible for developing a getwell plan. The Program Manager (PM) must identify problem failure modes and potential corrective actions to mitigate the occurrence of those failure modes.

- ATEC/AEC. In the event of a threshold breach, ATEC will lead an In-Progress Review (IPR) to: (1) review the PMO's planning and corrective action strategy; (2) project the reliability that would be achieved if the PM's proposed corrective actions are implemented and; (3) assess the risk of the program not getting back on track.

- AMSAA. AMSAA is identified to support AEC in identifying ownership cost impacts of the system given its current limitations. AMSAA can also serve as a member of source selection boards with subject matter expertise in the area of reliability engineering.

- TRADOC. The policy calls on TRADOC to assess the utility of the system given its current level of reliability maturity.

\subsection{Identification of Life Cycle Costs Impacts}

In the event of a threshold breach, the Army is required to identify the ownership cost impacts on the program. The key players in performing this cost analysis include: (1) the AMSAA Resource Studies Branch; (2) the AEC-ILS Directorate and; (3) the PMO. While not discussed in detail herein due to space limitations, the Army is identifying reliability impacts on LLC via AMSAA's COnsumption, HOlding, Repair and Transportation (COHORT) cost model, e.g., see $[10,11]$. All parties mentioned above must work together to establish the inputs that AMSAA will need to run the COHORT model. If the results from the AMSAA Scorecard evaluations (discussed in the next section) indicate high risk for one or more of the vendors, the RAM Subgroup should make advanced preparations in establishing the inputs for this LCC analysis.

\subsection{RELIABILITY ENGINEERING ACTIVITIES}

\subsection{Design for Reliability.}

During the early to mid 1980s, the U.S. automotive industry experienced an increase in warranty costs, and an erosion of its market share to Asian competitors. This was mainly a consequence of consumers demanding better product quality and reliability in their cars and trucks. To tackle these market pressures, as well as increasing Government mandates regulating automotive safety, fuel efficiency, and emissions control standards, manufacturers were faced with implementing companywide reliability improvement programs. These challenges resulted in the genesis of what is known as the Design for Reliability (DFR) process, e.g., see [14].

The DFR process encompasses the management and reliability engineering activities executed during the design stage. Fundamentally the DFR process is used to identify and characterize failure modes at the lowest indenture levels possible before system-level prototyping. The intention and importance of this is to understand, quantify, and mitigate failure mechanisms within subsystems, components, circuit boards etc. in order to avoid compounding reliability deficiencies through the integration of immature subassemblies. The main elements of a DFR program are covered in the remainder of this section. This material will undoubtedly help the practitioner become familiar with and recognize some of the primary reliability best practices that should be included in an RPP.

Figure 5 illustrates the DFR process given in [2] and identifies best practices that have proven to be invaluable for developing a reliable product. Note that this illustration and 
the associated activities by no means capture every management tool, engineering effort, or methodology within the DFR framework, nor are these actions specifically required by Army policy. These are simply the main reliability engineering efforts Materiel Developers and DoD vendors should have in their RPPs and execute early-on as part of a DFR program. The cycle begins with performing basic "Design Activities," and is followed by "Testing" (i.e., lower-level testing), "Tracking" (e.g., failures, failure modes, and design modifications), and "Assessment," or quantification of subsystem/component failure rates and reliabilities.

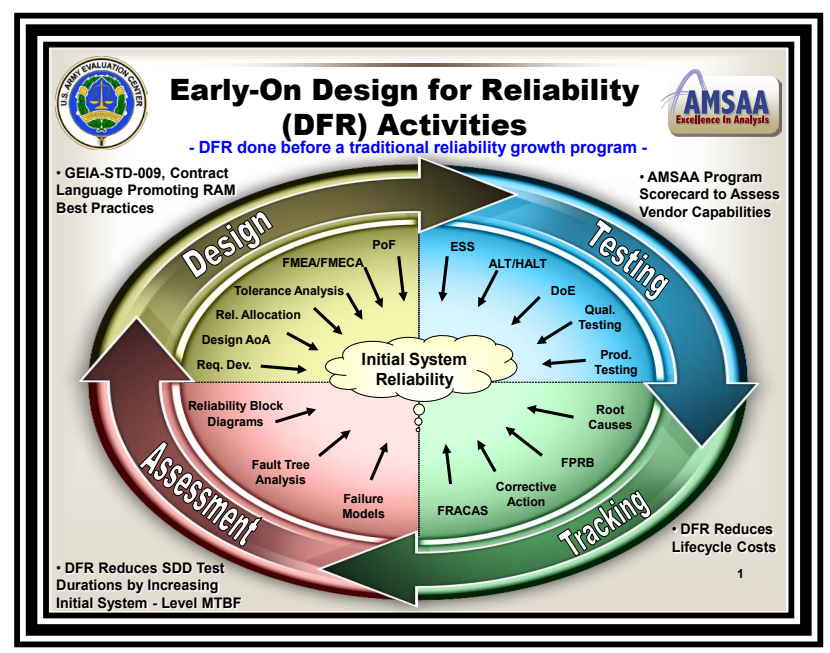

Figure 5. Design for Reliability Activities

Notice that the initial system reliability is located at the center of the cycle-diagram. The engineering activities noted in the figure are intended to design a specific targeted level of reliability into a product before system-level integration begins. Some systems may only require a DFR program to reach a given reliability requirement. More complex systems, however, may require both a DFR program, as well as a traditional $\mathrm{RG}$ program.

\subsection{Reliability Growth Management and Methodology}

Early prototypes of complex systems nearly always possess design and manufacturing deficiencies. To improve reliability and performance characteristics of developmental items, these initial weaknesses must be found, investigated, and eventually corrected. As a result, system prototypes are manufactured and subjected to a series of different tests, thereby exposing them to the envelope of stresses (e.g., mechanical, thermal, electrical, environmental, etc.) that the customer is likely to encounter in the operational environment. Once failure modes are identified, corrective actions are developed to mitigate (or sometimes eliminate) the occurrence of the failure modes. Such corrective actions, or fixes, undergo a rigorous review and approval process before they are applied to system prototypes. When the fixes are incorporated, the system typically returns to test in order to verify the redesign effort, as well as to uncover additional (remaining) failure modes.
This process of eliminating initial design (or manufacturing) weaknesses in a system via failure mode discovery, analysis, and effective correction is generally what is meant by reliability growth. Reliability Growth Management procedures, such as those prescribed in Military Handbook 189 [15], the AMSAA Reliability Growth Guide [16], and Appendix C of the DoD Guide for Achieving RAM [17] consist of the application of planning, tracking, and projection methods. Naturally, reliability improvements gained during development are heavily dependent upon the effectiveness of corrective actions applied to system prototypes. A corrective action typically consists of a design change or alteration to hardware, software, or human factors aspects of a system. Some examples include: (1) hardware fixes; (2) software fixes and; (3) human factors improvements. Regardless of the type of corrective action, a major performance indicator of the growth process entails the rate at which reliability is improved. The rate of reliability improvement is dependent upon several factors including (but not limited to):

- The rate at which failure modes are discovered during testing.

- The turnaround time associated with:

- Root cause failure analysis.

- Scoring of failure data via the users Failure Definition / Scoring Criteria (FD/SC).

- Development of corrective actions.

- Corrective action review and approval process.

- Potential changes in manufacturing process.

- Implementation of approved fixes.

- Management strategy (MS) or the fraction of the problem addressed.

- The effectiveness of corrective actions.

Clearly, all of the above are dependent on timely management commitment to allocate and reallocate programmatic resources (e.g., test hours, calendar time, and money), as needed. For example, early planning in terms of schedule and budget is required to successfully plan and fund required testing, failure analysis, as well as the development and implementation of the corrective actions. As mentioned previously, the implementation guide [2] has a much more thorough discussion of reliability growth and the various procedures for accounting for reliability growth.

\subsection{Reliability Language for DoD Acquisition Contracts.}

The first step necessary for establishing robust RAM programs is to hold contractors accountable for pursuing reliability best practices. This may be achieved by having appropriate language incorporated into the Request for Proposal (RFP), as well as the EMD contract solicitation. The new GEIA STD-0009 [3] was specifically developed to assist in the development of reliability contract language. The standard addresses the following area of an RFP:

- Section C Statement of Work Reliability Language and Tailoring Instructions

- Section L Proposal Instructions Reliability Language

- Section M Evaluation Factors for Award Reliability Language 
- Checklist for Evaluating Reliability Program Plans The development the GEIA-STD-0009 is an outcome of the DoD Reliability Improvement Working Group [5] and its use is encouraged by ASA(ALT). The language recommended by the GEIA will be helpful in formulating a systems engineering strategy with the desired focus on developing a system that meets or exceeds reliability requirements

\subsection{Early Engineering Evaluation.}

The ASA(ALT) policy [1] calls for a review of the materiel developer's reliability case documentation, and focuses on the use of reliability best practices. These analyses are essential elements of RPP as they help establish the technical maturity of the item under development with respect to reliability and provide a means to assess the developer's design for reliability process. The reliability case documentation is developed by the PM and should be reviewed by all members of the RAM Subgroup. Note the PM's RPP is typically developed in support of the reliability case documentation. The reliability case should outline "what the vendors should do" as opposed to "how they should do things". Some of these activities include (but are not limited to):

- Developing a RPP.

- Developing a system reliability model.

- Addressing systems-engineering integration issues.

- Characterizing operational and environmental loads at the system and subsystem levels.

- Identifying and characterizing failure modes throughout the life cycle.

- Closed-loop failure mode mitigation.

- Understanding failure definitions per the customerspecified Failure Definition.

- Reliability assessment throughout the life cycle.

- Reliability verification strategy.

- Conducting technical reviews throughout the life-cycle.

After learning "what the materiel developer has contracted the vendor to do," the next question is: Does the vendor's reliability engineering design processes support meeting the materiel developer's reliability expectations? AMSAA's Reliability Program Scorecard [4] has been specifically developed to facilitate this evaluation. It identifies appropriate methods, tools, and reliability activities that should be used in the following areas:

- Reliability requirements and planning

- Training and development

- Reliability analysis

- Reliability testing

- Supply-chain management

- Failure reporting and tracking

- Verification and validation

- Reliability improvements

The RAM Subgroup will need to conduct working-level meetings and/or site visits to assess the activities as either: (1) satisfactory (green); (2) acceptable (yellow) or; (3) unacceptable (red). The AMSAA Reliability Program Scorecard includes descriptions of each of these three risk categories for each of the above reliability activities. The
Scorecard is intended to provide a mechanism by which the user may obtain an overall understanding of (and degree of insight into) the vendor's reliability engineering capabilities and progress toward developing the desired contractdeliverable.

\section{CONCLUSION}

This paper has outlined the steps the Army has developed for implementing the new DA and DoD reliability initiatives. Information presented herein gives the reader an idea of the activities that are needed in a good Reliability Program Plan and how management can use such a plan to track the overall progress of the reliability development effort. Many of the concepts and procedures that have been discussed are common reliability engineering processes utilized in private industry. Additional details on the items discussed here are available from the U.S. Army Test and Evaluation Command or by contacting the authors.

\section{REFERENCES}

1. U.S. Department of the Army, memorandum, 6 December 2007, "Reliability of Army Material Systems", Washington, DC: Government Printing Office.

2. Hall, J.B., "Implementation Guide for U.S. Army Reliability Policy", Army Test and Evaluation Command, (June) 2009.

3. GEIA Standard 0009, "Standards on Reliability Program Standard for Systems Design, Development, and Manufacturing," 2008.

4. Defense Acquisition University, "AMSAA Reliability Program Scorecard," 2008, Available:

https://acc.dau.mil/CommunityBrowser.aspx?id=210483

5. U.S. Department of Defense, "Report of the Reliability Improvement Working Group", Washington, DC: Government Printing Office, 2008.

6. U.S. Department of Defense, "Defense Science Board Task Force Report on Developmental Test \& Evaluation", Washington, DC: Government Printing Office, 2008.

7. U. S. Department of Defense, "Operation of the Defense Acquisition System", DoD Instruction 5000.2, Washington, DC: Government Printing Office, 2008.

8. Ellner, P. M., and Hall, J. B., "Planning Model based on Projection Methodology (PM2)," Technical Report 2006-9, AMSAA, 2006.

9. Ellner, P. M., and Hall, J. B., "An Approach to Reliability Growth Planning based on Failure Mode Discovery and Correction using AMSAA Projection Methodology," IEEE Proc. RAMS, pp. 266-272, 2006.

10. Kotkin, M., "Visual SESAME 2.0 The Provisioning Tool for the $21^{\text {st }}$ Century User's Guide", Technical Report 114, AMSAA, 2001.

11. Kotkin, M., "The SESAME based Life Cycle Spares and Repair Cost Program (SESLCC)," Technical Report 2006-30, AMSAA, 2006.

12. U.S. Department of Defense, memorandum, 21 July 2008, "Reliability, Availability, and Maintainability Policy," Washington, DC: Government Printing Office. 
13. Weapon System Acquisition Reform Act, Public Law 111-23, (May) 2009.

14. Ireson, W. G., Coombs, C. F., and Moss, R. Y.,, "Design for Reliability", in Handbook of Reliability Engineering and Management (2nd ed.), pp. 5.1-5.16, 1996.

15. U.S. Department of Defense, "Reliability Growth Management", Military Handbook 189, Washington, DC: Government Printing Office, 1981.

16. Ellner, P. M., Broemm, W. J., and Woodworth, W. J., "Reliability Growth Guide", Technical Report 652, AMSAA, 2000.

17. U.S. Department of Defense, "DoD Guide for Achieving Reliability, Availability and Maintainability", Washington, DC: Government Printing Office, 2005.

\section{BIOGRAPHIES}

Mr. Ken Dalton

U.S. Army Evaluation Center (AEC)

TEAE-REG, 4120 Susquehanna Avenue

Aberdeen Proving Ground, MD, 21005-3013, USA

e-mail: ken.dalton@us.army.mil

Mr. Dalton is the Division Chief for Ground Combat and Fire Support Systems in the Reliability \& Maintainability (RAM) Directorate, AEC. He has Bachelor of Science Degree in Electronics Engineering from Christian Brothers University and Master of Engineering Degree in Industrial Engineering from Texas A\&M University. Mr. Dalton has worked for 35 years for the U.S. Army on a wide range of Army equipment. Mr. Dalton has helped formulate and implement a variety of reliability policies, and contributed towards several reliability standards.
J. Brian Hall, Ph.D.

U.S. Army Evaluation Center

TEAE-REA, 4120 Susquehanna Avenue

Aberdeen Proving Ground, MD, 21005-3013, USA

e-mail: brian.hall@us.army.mil

J. Brian Hall, Ph.D. is the Division Chief for Aviation, Missiles, and C3I Systems in the RAM Directorate, AEC. He has worked for the Department of the Army for over 10 years (i.e., 8 years with AMSAA, and over 2 years with AEC). Dr. Hall has developed and published a number of new methods in the area of reliability growth, developed implementation guidance for U.S. Army reliability policy, and has authored or made technical contributions to a variety of works, such as, the revision of Military Handbook 189, the OSD Guide for Achieving RAM, ATEC policy on reliability growth planning, AMSAA Technical Reports, ATEC System Evaluation Reports, conference proceedings, and refereed journal articles.

Dr. Hall earned a B.S. in Mathematics from Loyola College, and a M.S. in Mathematics from the Whiting School at The Johns Hopkins University; Baltimore, Maryland. He also holds a Ph.D. and a 2nd M.S. degree in Engineering Reliability from the University of Maryland, College Park. Dr. Hall is a graduate of the U.S. Army Logistics Management College; Fort Lee, VA, as well as the U.S. Army Management Staff College; Fort Belvoir, VA. He is a certified member of the Defense Acquisition Corps with Level III Certifications in both Systems Engineering, and Test \& Evaluation. He is a member of the Phi Kappa Phi, Tau Beta Pi, and Magna Cum Laude National Scholars Honor Societies and was the 2009 recipient of the Ralph A. Evans / P.K. McElroy RAMS Best Paper Award. Dr. Hall is married to the former Alyson Taylor Moore. 